Article

\title{
Incident Causal Factors and the Reasons for Conducting Investigations: A Study of Five Ghanaian Large-Scale Mines
}

\author{
Eric Stemn ${ }^{1,2, *}$, Florence Ntsiful ${ }^{1}$, Marconi Afenyo Azadah ${ }^{1}$ and Theophilus Joe-Asare ${ }^{1}$ \\ 1 Environmental and Safety Engineering Department, University of Mines and Technology, Tarkwa Box 237, \\ Ghana; florencentsiful@gmail.com (F.N.); marconi.azadah@gmail.com (M.A.A.); \\ tjoe-asare@umat.edu.gh (T.J.-A.) \\ 2 Minerals Industry Safety and Health Centre, Sustainable Minerals Institute, The University of Queensland, \\ Brisbane, QLD 4072, Australia \\ * Correspondence: estemn@umat.edu.gh or e.stemn@uq.edu.au; Tel.: +23-354-930-6669
}

Received: 21 November 2019; Accepted: 28 January 2020; Published: 6 February 2020

\begin{abstract}
Background: This research sought to understand the perspective of mineworkers regarding incident investigations, with the objective of identifying incident investigations improvement opportunities. First, through interviews, the research sought to identify the causal factors considered during investigations and the reasons for conducting investigations in the Ghanaian mining industry. Secondly, through questionnaire surveys, the study focused on understanding the extent to which a large sample of mineworkers considered the identified causal factors and investigation reasons relevant and applicable in their mine. Method: Data were collected from 41 participants through interviews and 659 respondents through surveys, and the data were analyzed through thematic, content, and statistical analyses, including descriptive statistics, one-way ANOVA, and correlation analysis. Result: The interviews led to the identification of five and nine categories of incident causal factors and reasons for investigating incidents, respectively. The results suggested a focus on workers' unsafe acts as the main incident causal factor and identifying the person who caused the incident as one of the major reasons for investigating incidents, as these two factors where the modal choice from both the interviews and survey across all five mines. The results further showed that concerning the accident causal factors and the reasons for investigating incidents, no significant difference was observed between the perspectives of mineworkers involved in investigations and mineworkers with no investigation responsibilities. Conclusion: It can be concluded from the results that talking to ordinary mineworkers does not generate innovative safety responses in this context, as the workers believe whatever they are taught, without critiquing it. Again, the focus on workers' behavior as an accident causal factor is an indication of single-loop learning in contrast to double-loop learning, and its implication as well as opportunities to strengthen incident investigation focusing on improving organizational safety have been discussed.
\end{abstract}

Keywords: incident causal factors; unsafe acts; compliance; Ghanaian mining industry; incident investigation

\section{Introduction}

Over the last two decades, there have been growing researcher and practitioner interests in learning more broadly from incidents and incident investigations specifically. This is because incident investigation has been recognized as an important means of improving organizational safety [1-6]. For instance, the mere identification and reporting of an incident which has occurred can lead to the identification of organizational weaknesses and means of preventing a recurrence of the incident 
to improve the safety performance of the organization. Again, incident investigations suggest that incidents are analyzed to identify lessons (the causal factors that contributed to the incidents), and, on the basis of identified lessons, recommendations, which when acted upon can prevent future incidents, are formulated and implemented [7-10]. Therefore, incidents must not be seen as dissatisfactions, but rather as a learning input, a free lesson, and a potential opportunity to focus efforts to improve the current organizational safety level [11]. These and several other reasons have accounted for the recent focus and growing interest in incident investigation research. Previous research has focused primarily on analyzing specific past major accidents and disasters to identify lessons for improving safety [12-16]. Still, others have focused on the incident analysis techniques used in identifying lessons [17-20], and recently on the follow-up stage after the identification of incident causal factors [2,21-24]. All these studies have contributed greatly in reducing incident frequency and severity across several industries [25], as well as improving our understanding of organizational learning from incidents. However, improvement opportunities still exist, particularly understanding and improving the incident investigation perceptions of ordinary workers (regarding incident causal factors and the reasons for investigating incidents) who do not have incident investigation responsibilities.

Studies that report the perspectives of workers on incident investigation are scanty. Most of the existing research focuses on the perspectives of workers who are deeply involved in investigation, with lack of focus on workers who play a role in investigation but are not deeply involved, such as incident victims and witnesses. A focus on the incident investigation perspectives of such workers could contribute to strengthening effective investigation to improve safety. For instance, previous studies, which report the perspectives of incident investigators in the Ghanaian mining industry (GMI), identified several issues confronting effective investigation and proposed recommendations for overcoming the identified investigation challenges. Some of the issues identified included lack of investigation training, lack of knowledge on accident causation models, limited use of relevant information/data sources, and using the investigation process to identify violation to recommend punishment. Again, it has been reported that the perceptions of ordinary workers concerning incident investigations affect the investigation culture of the organization and the individual commitment toward incidents investigations [11,26,27]. However, those past studies report the perspectives of workers deeply involved in incident investigations, without any considerations to the perspectives of ordinary workers with no investigation responsibilities. An understanding of the current perceptions of such workers regarding investigations could contribute to identifying further incident investigation improvement opportunities.

This research therefore sought to contribute to the narrow focus on the perspectives of ordinary workers on incident investigations. The primary objective of the study was to investigate whether talking to ordinary mineworkers could produce new and meaningful knowledge regarding incident causal factors and reasons for investigating incidents that could improve organizational safety. The study sought to elicit the perspective of mineworkers on incident investigations, specifically their perceptions on the causes of incidents and the reasons for investigating incidents. The research was formulated and implemented based on the following questions:

- What factors are considered as incident causal factors in Ghanaian mines and to what extent are these causal factors considered/identified during actual investigations?

- What factors are regarded by mineworkers as the reasons for investigating the incident and to what extent are these factors considered important?

- Are there any differences in the responses of different mineworker groups regarding incident causal factors and reasons for investigating an incident?

- Are there any associations between the perceived incident causal factors and the reasons for conducting incident investigations?

In Ghana, there is a growing concern for mine safety due to the recent occurrences of fatal accidents in the industry. For instance, a collapse of the roof of a tunnel at the Newmont Ahafo mine in April 
2018 resulted in the death of six workers, with four others severely injured [28,29]. The Chief Executive Officer of the Ghana Chamber of Mines indicated an increase in the annual fatality of the industry from three in 2016 to five in 2017 [30]. These increasing fatalities support the need to focus on mine safety, forming part of the basis of this research to understand what factors are considered as the causes of these accidents and how they are investigated to identify opportunities to improve safety.

\section{Materials and Methods}

Since this study, to some extent, was multidisciplinary in nature, a combination of qualitative and quantitative methods was adopted for data collection to obtain an in-depth understanding of the research questions. This paper presents findings from both qualitative and quantitative studies.

\subsection{Selection of Case Study Mines}

The study focused on the Ghanaian (large-scale) mining industry as it is one of the most highly regulated industries in the country regarding occupational health and safety. Again, the other justification for focusing on the mining industry is due to the contribution of mining to the Ghanaian economy [31] and the recent upsurge of investment in the GMI, which does not only present huge economic benefits, but also a number of challenges, notably in the area of health and safety of the workforce [32-34]. The occurrence of work-related accidents results in huge losses to the industry. These losses could potentially affect the revenue the industry generates and subsequently impact the industry's contribution to the socioeconomic development of the country. Therefore, any attempt to improve the safety performance of the industry is a worthy course.

Purposive and convenience sampling techniques were used to select five large-scale gold mines at different locations in Ghana. First, two selection criteria were defined for the mines, that is (1) the owner of the mine should be a member of the Ghana Chamber of Mines (GCM) and reporting to the Inspectorate Division of the Minerals Commission of Ghana (IDMC) (the jurisdictional authority) and (2) the mining company should have been engaged in actual mining operations for a minimum of 10 continuous years. Membership of the GCM and reporting to the IDMC was to ensure that only legitimate companies were selected to participate in the research. The 10-year criterion was to ensure that the company has been operating long enough to have instituted an incident management plan, including investigating several incidents. Introductory letters containing information about the research were subsequently distributed to 12 mines belonging to 8 different mining companies that met the two selection criteria. After several follow-ups, five mines belonging to five different mining companies indicated their willingness and readiness to participate in the research. As can be seen in Table 1, all five mines that participated in the research were owned by multinational companies. All five mines are large-scale metalliferous gold mines, with three of them $(\mathrm{A}, \mathrm{C}$, and $\mathrm{E})$ operating an open-pit mining method, with the remaining two mines (B and $D$ ) having transitioned from open-pit mining to underground operations through a ramp system. Regarding how the ore is processed, Mines B, C, D, and E operate a conventional carbon-in-leach (CIL) milling operation, whereas Mine A operates a carbon-in-pulp processing plant.

\subsection{Data Collection}

\subsubsection{Qualitative Study}

Initial semi-structure face-to-face individual interviews were conducted with 41 relevant workers across the five mines. The interview participants consisted mainly of workers with and without core safety jobs who are deeply involved in incident investigations. Thus, the interview participants were satisfactory sources of information regarding incident investigations in the mines. The interview questions covered two main topics, namely, (1) the causal factors identified from incident investigations, and (2) the reasons for investigating incidents. All interviews were held at the respective mines, at a specific location preferred by the interviewee. Averagely, an interview lasted $10 \mathrm{~min}$ and was audio 
recorded at the written consent of the interviewees. To improve the credibility of the participants' responses, the researcher spent an extensive period (at least a week, with an opportunity of returning to the mines to validate preliminary findings) at each of the mines. During this period, intimacy and rapport gradually developed between the researcher and the research participants to the point where participants voluntarily and willingly shared information, including sensitive material they were unwilling to share at the early stages of the interviews. The participants of the research had varied experiences increasing the possibility of providing insights relating to the research questions from a variety of perspectives $[35,36]$. Participants of different ages, genders, organizational levels, experiences, and perspectives contributed to a richer variation and understanding of the research topic.

\subsubsection{Quantitative Study Design and Distributions of Questionnaires}

Results obtained from analyzing the interviews were used to design a quantitative study. The quantitative study involved the design and administration of questionnaires to a large sample of mineworkers across the five selected mines to determine their perspectives on the incident causal factors and the incident investigation reasons identified from the qualitative study. A multi-item questionnaire was distributed to a random sample of 720 employees across the five mines, during tool-box meeting, lunch breaks, safety training, and personal visits to offices and working areas during working hours. The questionnaire consisted of ten items, grouped into four sections, namely, (1) demography, (2) investigation experience, (3) incident causal factors, and (4) reasons for investigating incidents, as shown in Appendix A. Since English is the official medium of instruction in all Ghanaian schools and the participants could read and write English, all questionnaires were administered in English. Questionnaires were anonymous and participants were informed of the ethical considerations of the research, including confidentiality, anonymity, and voluntary participation, and their written consent was obtained prior to their participation in the research. Ethical approval was obtained from the Sustainable Minerals Institute (University of Queensland) Student Research Ethics Committee prior to data collection.

Table 1. Distribution of responses across the five participating mines.

\begin{tabular}{ccccccc}
\hline Mine & Type of Mine & $\begin{array}{c}\text { Number of } \\
\text { Employees }\end{array}$ & $\begin{array}{c}\text { Number of } \\
\text { Interviews }\end{array}$ & $\begin{array}{c}\text { Distributed } \\
\text { Questionnaires }\end{array}$ & $\begin{array}{c}\text { Analyzed } \\
\text { Questionnaires }\end{array}$ & $\begin{array}{c}\text { Response } \\
\text { Rate }\end{array}$ \\
\hline A & $\begin{array}{c}\text { Multinational with } \\
\text { multiple sites }\end{array}$ & 1872 & 10 & 146 & 135 & $92.5 \%$ \\
\hline B & $\begin{array}{c}\text { Multinational with } \\
\text { single site }\end{array}$ & 1750 & 8 & 141 & 128 & $90.8 \%$ \\
\hline C & $\begin{array}{c}\text { Multinational with } \\
\text { multiple sites }\end{array}$ & 4892 & 12 & 201 & 184 & $91.5 \%$ \\
\hline D & $\begin{array}{c}\text { Multinational with } \\
\text { multiple sites }\end{array}$ & 1603 & 6 & 114 & 104 & $91.2 \%$ \\
\hline E & $\begin{array}{c}\text { Multinational with } \\
\text { multiple sites }\end{array}$ & 1400 & 5 & 118 & 108 & $91.5 \%$ \\
\hline & Total & 11,517 & 41 & 720 & 659 & $91.5 \%$ \\
\hline
\end{tabular}

A total of 659 questionnaires were correctly completed and returned, representing a response rate of $91.5 \%$. The administration procedure adopted accounted for this high response rate, as participants did not have the flexibility of deferring their responses to later dates. Since all the mines practice a decentralized safety management, each department had at least one safety officer, who collected bulk questionnaires and distributed them to workers in their department. The first author spent at least a week at each mine distributing and collecting completed questionnaires. The characteristics of the five participating mines, as well as their distribution of responses is presented in Table 1. 


\subsection{Data Analysis}

\subsubsection{Interviews}

The interviews were transcribed verbatim to capture exactly what the interviewees said, and subsequently analyzed following the thematic and qualitative content analysis techniques [35,37-40]. The text was first grouped into two broad topics, namely, (1) incident causal factors and (2) reasons for investigating incidents. The text under each of the topics was then read to get a sense of the whole and inductively coding the text. The inductive coding involved reading and dividing the text into "chunks" of words and describing each chunk with a word/phrase descriptor that indicate the meaning of the chunk. This was an iterative process, involving going back to already coded text to compare codes. This inductive coding was repeated for all 41 interviews, with codes being constantly compared to remove redundant codes and group similar codes, until a coding structure applicable to all the interviews was developed [11]. This led to the identification of 5 and 9 categories of incident causal factors and reasons for investigating incidents, respectively. The result of this analysis was then quantified by counting the number of participants who commented on a particular category.

\subsubsection{Questionnaires}

Data from the questionnaire survey was manually coded by assigning values to the participants' responses and entered into SPSS v22 for onward analysis. In the questionnaire, the participants' responses were elicited using a 5-point Likert scale; Never (1), Seldom (2), Sometimes (3), Often (4), and Always (5) for the causal factor question, and Not Important (1), Slightly Important (2), Moderately Important (3), Important (4), and Very Important (5) for the reasons for investigating question (see Appendix A). Therefore, the analysis focused on identifying patterns, trends, and associations in the responses to those two questions. First, the percentages of responses for each of the five options for each of the causal factors and investigation reasons were determined for each mine, and then for the whole cohort. Secondly, one-way analysis of variance (ANOVA) was used to determine if any statistically significant difference existed between responses from different groups. If a statistically significant difference was found, Turkey's HSD post hoc test was undertaken to determine the specific groups where those differences existed. Finally, Pearson's correlation analysis was used to determine if any association existed between the perceived incident causal factors and the reasons for investigating incidents.

\section{Results}

\subsection{Participant Characteristics}

\subsubsection{Interviews}

Out of the 41 interview participants, 33 were males, 8 were females; 27, 9, and 3 were frontline supervisors, middle managers, and top managers, respectively. Although all the interviewees were deeply involved in the incident investigations at the mines, they played different roles. A total of 34 of them had core safety jobs, whereas the remaining seven did not have core safety jobs. Averagely, the participants had 10 years of investigation experience within the mining industry and the majority (33) of them had been recently (at most a year) involved in incident investigations. Figure 1 presents sample characteristics of the interviewees across the mines. 


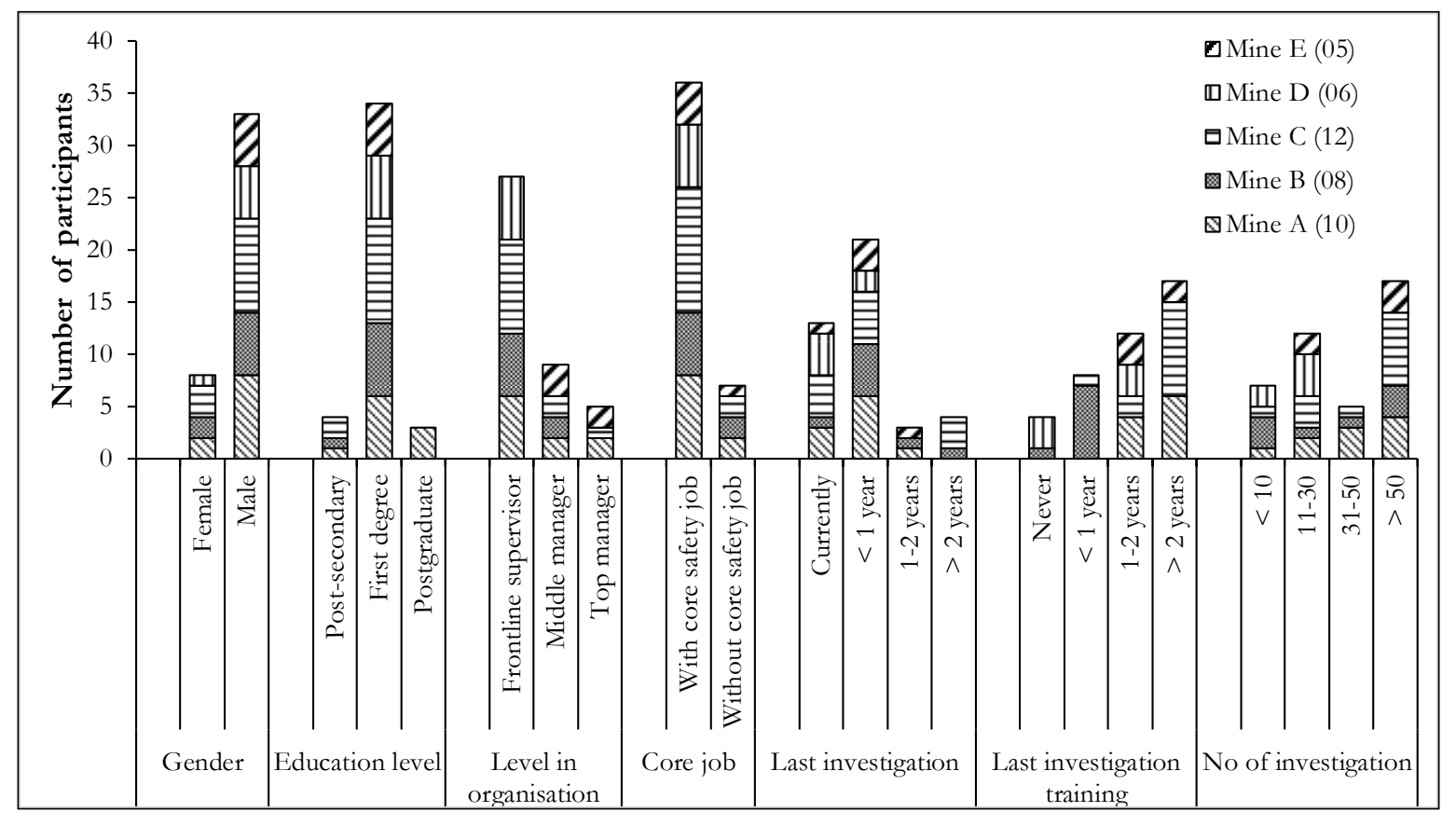

Figure 1. Comparison across mines of the characteristics of the interview participants.

\subsubsection{Questionnaire Surveys}

A total of $82.2 \%$ of the survey respondents were males, with the remaining $17.8 \%$ being females, which is representative of the female-male ratio of the Ghanaian mining industry [27,31,41]. Most (83.3\%) of the respondents were young miners (below 40 years), while $26.7 \%$ were at least 40 years. A total of $63.1 \%$ had technical roles (i.e., mining operation and mineral processing), with the remaining $36.9 \%$ offering support services (e.g., maintenance, health, safety, and environment). Regarding their incidents and investigation experience, $48.3 \%$ indicated they had neither been involved in an accident nor investigating incidents, while the remaining $51.7 \%$ had experienced incidents in the past and/or been involved in investigating different incidents. Concerning their organization levels, over $80 \%$ were either frontline employees or supervisors, with a few $(16.4 \%)$ of them occupying middle/top managerial roles. The demographic characteristics of the survey participants is shown in Table 2.

Table 2. Comparison across mines of the characteristics of the questionnaire survey participants.

\begin{tabular}{lcccccc}
\hline \multirow{2}{*}{ Characteristic } & \multicolumn{5}{c}{ Number (Percentage) of Responses from Mines } \\
\cline { 2 - 6 } & Mine A & Mine B & Mine C & Mine D & Mine E & Whole Cohort \\
\hline Gender & & & & & & \\
\hline Male & $106(78.5)$ & $110(85.9)$ & $144(78.3)$ & $89(85.6)$ & $93(86.1)$ & $542(82.2)$ \\
Female & $29(21.5)$ & $18(14.1)$ & $40(21.7)$ & $15(14.4)$ & $15(13.9)$ & $117(17.8)$ \\
\hline Age & & & & & & \\
\hline $18-30$ & $58(43)$ & $68(53.1)$ & $97(52.7)$ & $38(36.5)$ & $38(35.2)$ & $299(45.4)$ \\
$30-39$ & $70(51.9)$ & $49(38.3)$ & $38(20.7)$ & $49(47.1)$ & $44(40.7)$ & $250(37.9)$ \\
$40-49$ & $4(3.0)$ & $9(7.0)$ & $42(22.8)$ & $15(14.4)$ & $23(21.3)$ & $93(14.1)$ \\
$49+$ & $3(2.2)$ & $2(1.6)$ & $7(3.8)$ & $2(1.9)$ & $3(2.8)$ & $17(2.6)$ \\
\hline
\end{tabular}


Table 2. Cont.

\begin{tabular}{|c|c|c|c|c|c|c|}
\hline \multirow{2}{*}{ Characteristic } & \multicolumn{6}{|c|}{ Number (Percentage) of Responses from Mines } \\
\hline & Mine A & Mine B & Mine C & Mine D & Mine $\mathrm{E}$ & Whole Cohort \\
\hline \multicolumn{7}{|l|}{ Investigation experience } \\
\hline None & $74(54.8)$ & $57(44.5)$ & $117(63.6)$ & $40(38.5)$ & $30(27.8)$ & 318 (48.3) \\
\hline Currently & $15(11.1)$ & $16(12.5)$ & $26(14.1)$ & $26(25)$ & $6(5.6)$ & $89(13.5)$ \\
\hline Last 3 months & $21(15.6)$ & $16(12.5)$ & $11(6)$ & $14(13.5)$ & $18(16.7)$ & $80(12.1)$ \\
\hline 3-6 months ago & $8(5.9)$ & $14(10.9)$ & $5(2.7)$ & $4(3.8)$ & $4(3.7)$ & $35(5.3)$ \\
\hline 6-12 months ago & $12(8.9)$ & $5(3.9)$ & $5(2.7)$ & $8(7.7)$ & $16(14.8)$ & $46(7)$ \\
\hline $1-2$ years ago & $0(0)$ & $14(10.9)$ & $13(7.1)$ & $9(8.7)$ & $26(24.1)$ & $62(9.4)$ \\
\hline $2-5$ years ago & $5(3.7)$ & $4(3.1)$ & $6(3.3)$ & $3(2.9)$ & $3(2.8)$ & $21(3.2)$ \\
\hline $5+$ years ago & $0(0.0)$ & $2(1.6)$ & $1(0.5)$ & $0(0.0)$ & $5(4.6)$ & $8(1.2)$ \\
\hline \multicolumn{7}{|l|}{ Number of investigations } \\
\hline None & $74(54.8)$ & $57(44.5)$ & $117(63.6)$ & $40(38.5)$ & $30(27.8)$ & $318(48.3)$ \\
\hline $1-10$ & $29(21.5)$ & $47(36.7)$ & $49(26.6)$ & $17(16.3)$ & $49(45.4)$ & $191(29)$ \\
\hline $11-20$ & $9(6.7)$ & $8(6.3)$ & $2(1.1)$ & $18(17.3)$ & $12(11.1)$ & $49(7.4)$ \\
\hline $21-30$ & $8(5.9)$ & $2(1.6)$ & $5(2.7)$ & $9(8.7)$ & $4(3.7)$ & $28(4.2)$ \\
\hline $31-40$ & $4(3.0)$ & $1(0.8)$ & $2(1.1)$ & $4(3.8)$ & $6(5.6)$ & $17(2.6)$ \\
\hline $40+$ & $11(8.1)$ & $13(10.2)$ & $9(4.9)$ & $16(15.4)$ & $7(6.5)$ & $56(8.5)$ \\
\hline \multicolumn{7}{|l|}{ Level in organization } \\
\hline Frontline worker & $39(28.9)$ & $75(58.6)$ & $117(63.6)$ & $46(44.2)$ & $49(45.4)$ & $326(49.5)$ \\
\hline Frontline supervisor & $71(52.6)$ & $43(33.6)$ & $45(24.5)$ & $37(35.6)$ & $29(26.9)$ & $225(34.1)$ \\
\hline Middle manager & $21(15.6)$ & $4(3.1)$ & $17(9.2)$ & $17(16.3)$ & $23(21.3)$ & $82(12.4)$ \\
\hline Top/Senior manager & $4(3.0)$ & $6(4.7)$ & $5(2.7)$ & $4(3.8)$ & $7(6.5)$ & $26(3.9)$ \\
\hline \multicolumn{7}{|l|}{ Workgroup } \\
\hline Mining operations & $72(53.3)$ & $70(54.7)$ & $93(50.5)$ & $44(42.3)$ & $48(44.4)$ & $327(49.6)$ \\
\hline Mineral processing & $12(8.9)$ & $16(12.5)$ & $16(8.7)$ & $18(17.3)$ & $27(25)$ & $89(13.5)$ \\
\hline Maintenance \& Engineering & $12(8.9)$ & 15 (11.7) & $14(7.6)$ & $18(17.3)$ & $14(13)$ & $73(11.1)$ \\
\hline Environment, Health \& Safety & $27(20.0)$ & 15 (11.7) & $39(21.2)$ & $11(10.6)$ & $12(11.1)$ & $104(15.8)$ \\
\hline Other services & $12(8.9)$ & $12(9.4)$ & $22(12)$ & $13(12.5)$ & $7(6.5)$ & $66(10.0)$ \\
\hline
\end{tabular}

\subsection{Qualitative Study (Interviews)}

\subsubsection{Incident Causal Factors}

The analysis of the interview data led to the identification of five and nine broad categories of incident causal factors and reasons for investigating incidents, respectively. The number of participants who responded to the categories of causal factors are presented in Figure 2. Figure 2 indicates that across the mines, there was focus on unsafe acts of workers and equipment-related issues as an incident causal factor, as that was commented upon by $41 / 41$ and 34/41 interviewees respectively, across all five mines. However, only 22/41 interviewees considered management and organizational related factors as an important incident causal factor. These results illustrate that across the mines, particularly at Mines $B, C$, and D, there is a focus on the proximate causes of incident during the investigation in contrast to latent causal factors, which is not so obvious to investigators [42]. This indicates that across the mines, the opportunity to improve safety through better incident investigations that focuses on latent incident causal factors exist.

\subsubsection{Reasons for Investigating Incidents}

Concerning the perceived reasons for investigating incidents, different responses were received as exemplified in Figure 3. Figure 3 shows that among the nine identified reasons, finding the causes of the incident and preventing future incidents were the most frequent reasons, mentioned by all 41 interviewees. Again, compliance related reasons were also among the frequently mentioned reasons (mentioned by at least 35/41 respondents), indicating that investigations are instigated to comply with 
the necessary legal and company requirements. Surprisingly, 31/41 investigators explicitly mentioned that the reason for undertaking investigations is to find the person who caused the accident and recommend appropriate punishment, although it has been reported in a related study that the use of punishment inhibits effective investigations in this context [41]. The figure further indicates that, across the mines, there was a lack of focus on finding systematic causes, reducing risk, strengthening risk controls, and advancing safety during incident investigations.

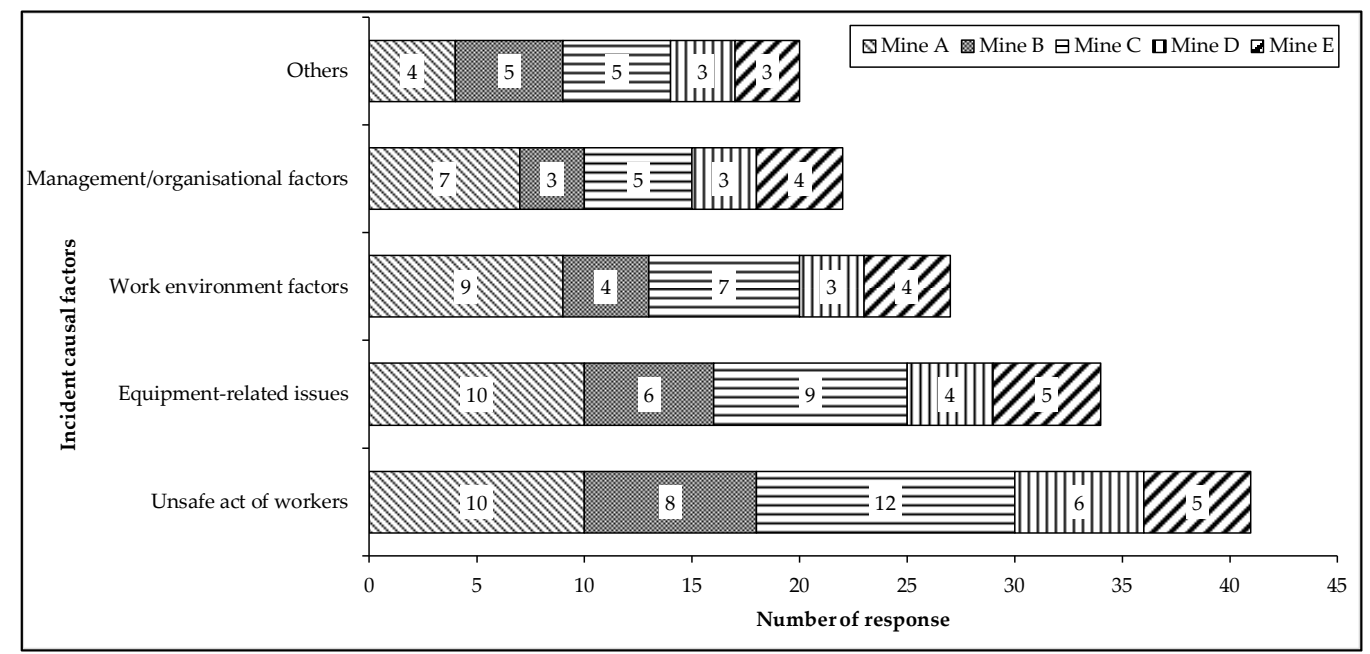

Figure 2. Comparison across mines of incident causal factors.

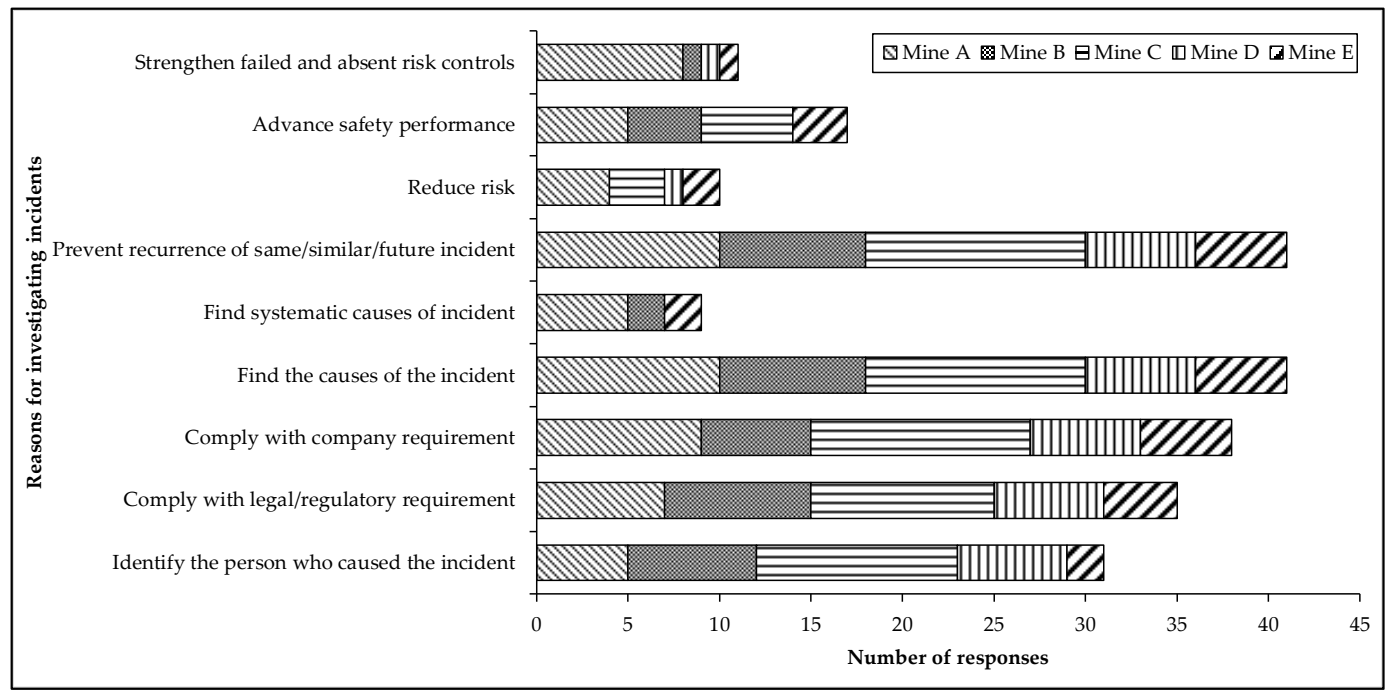

Figure 3. Comparison of the reasons for investigating incidents.

\subsection{Quantitative Study (Questionnaire Surveys)}

\subsubsection{How Often the Causal Factors are Identified during Investigation}

Figure 4 shows the 659 survey participants' responses to each of the five identified incident causal factors for each of the mines. It illustrates characteristics from the lowest ( $1-$ Never) to the highest (5-Always) level of consideration of the causal factors. For the unsafe act and organizational related causal factors, there were similar responses across the mines. For instance, for the unsafe act causal factor, the responses across all the mines showed less characteristics of the lower level (never, seldom, sometimes) of consideration and more characteristics of the highest level (often, always) of 
consideration. Specifically, 69.9\%, 63.3\%, 52.7\%, 91.3\%, and 72.2\% of the participants from Mines A, B, C, D, and E, respectively, indicated that an unsafe act of workers is either often or always identified as an incident causal factor from incident investigations at their mine. Conversely, the organizational factor shows more characteristics of the lower level of consideration and less characteristics of the higher level of consideration across the mines. Moreover, 91.9\%, 71.8\%, 70.1\%, 89.4\% and $81.4 \%$ of the respondents from Mines A, B, C, D, and E, respectively, indicated that organizational factors are never/seldom/sometimes considered as a causal factor in their investigations. This signifies that only $8.1 \%, 28.1 \%, 29.4 \%, 10.5 \%$, and $18.6 \%$ of the respondents from Mines A, B, C, D, and E, respectively, indicated that organizational factors are often/always identified as incident causal factors. These results compliment that of the interviews and further suggest that incident investigation improvement opportunities exist across the mines, particularly the narrow focus on organizational factors as incident causal factors remains a priority issue. Again, this result when compared to the responses from the interviews show that there is not much difference between the perspectives of workers deeply involved in investigations and the perspectives of workers with limited/no incident investigation responsibilities.

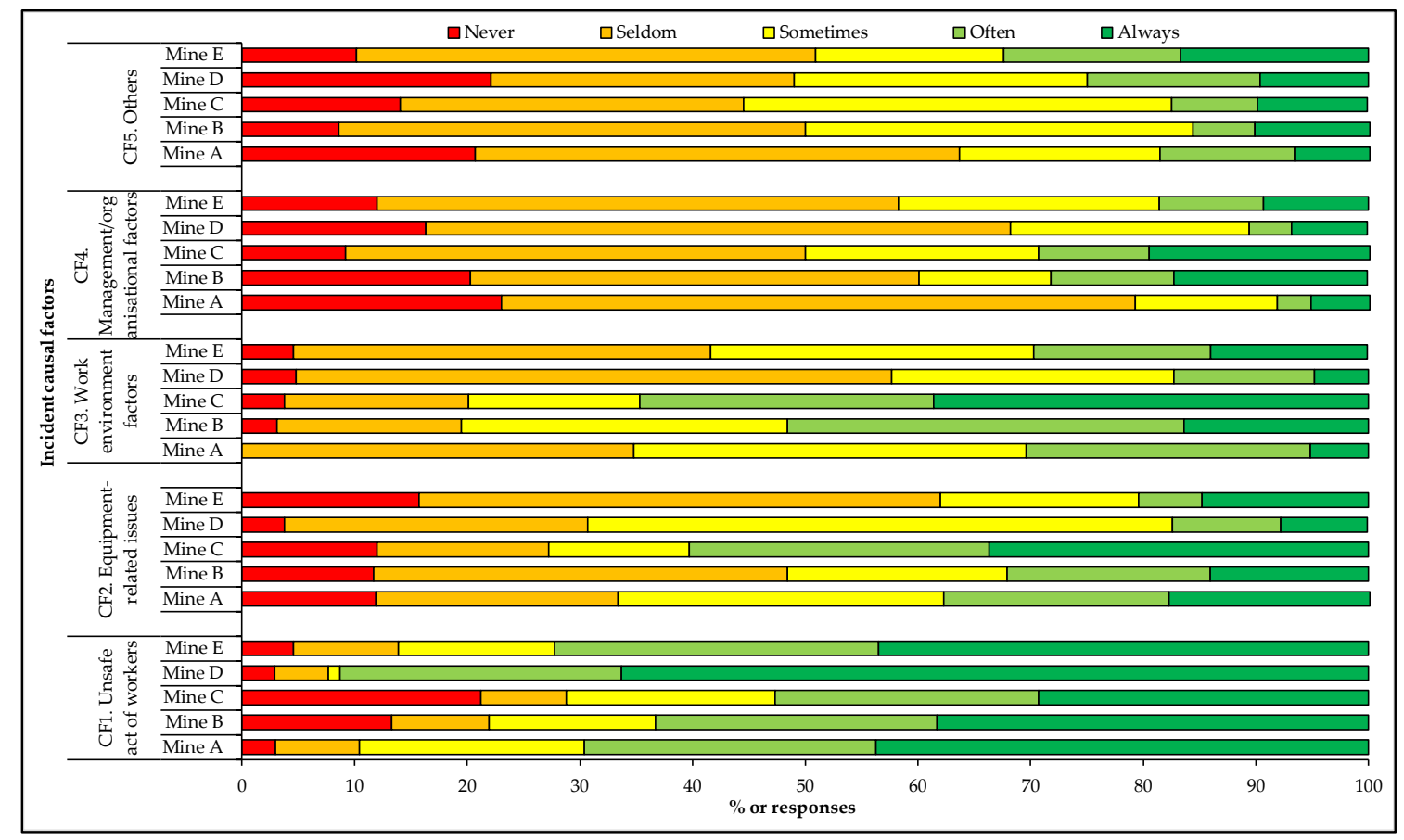

Figure 4. Comparison across mines of how often the survey participants perceived the incident causal factors to be identified during investigations.

For the equipment and work environment related causal factors, there were varied responses across the mines. For instance, whereas $37.8 \%$ and $32.1 \%$ of the respondents from Mines $\mathrm{A}$ and $\mathrm{B}$, respectively, selected often/always as their preferred choice for equipment-related issues as an incident causal factor, often/always was selected by $60.3 \%$ of the respondents from Mine C. Similarly, $30.4 \%, 51.6 \%, 64.7 \%, 17.3 \%$, and $29.6 \%$ of the participants from Mines A, B, C, D, and E, respectively, indicated that work environmental issues are often/always identified as an incident causal factor from investigations at their mines. This further suggests a narrow focus on work environmental factors during incident analysis to identify causal factors, particularly at Mines A, D, and E.

\subsubsection{How Important are the Reasons for Investigating Incidents}

Figure 5 shows the participants responses to each of the nine identified reasons for investigating incidents across the five mines. It depicts characteristics from the lowest (1-Not Important) to the highest (5-Very Important) level of consideration of the investigation reasons. For the "identification 
of the person involved" reason, the modal choice for Mines A, B, C, and E was "very important" and was selected by $31.1 \%, 39.1 \%, 53.8 \%$, and $30.6 \%$ of the respondents, respectively, indicating a strong focus on the incident victim. Figure 5 further indicates that compliance to regulatory and company requirements underpins the incident investigations conducted across the mines, as at least $50 \%$ of the respondents across the five mines indicated that complying to regulatory/company requirements is an important/very important reason for investigating incidents. Across the mines, it appears the most important reason for investigating incidents is to find causes to prevent future incidents, since "most important" was the modal choice for most (at least 52\%) of the respondents for the "find the causes of the incident" and "prevent future recurrent" reasons. Although there were varied responses for the "reduce risk", "advance safety performance", and "strengthen risk control" reasons across the mines, the responses generally suggest that those reasons were not that important when investigating incidents, since only a few (at most 44\%) respondents selected "important/most important" as their preferred choice for those reasons.

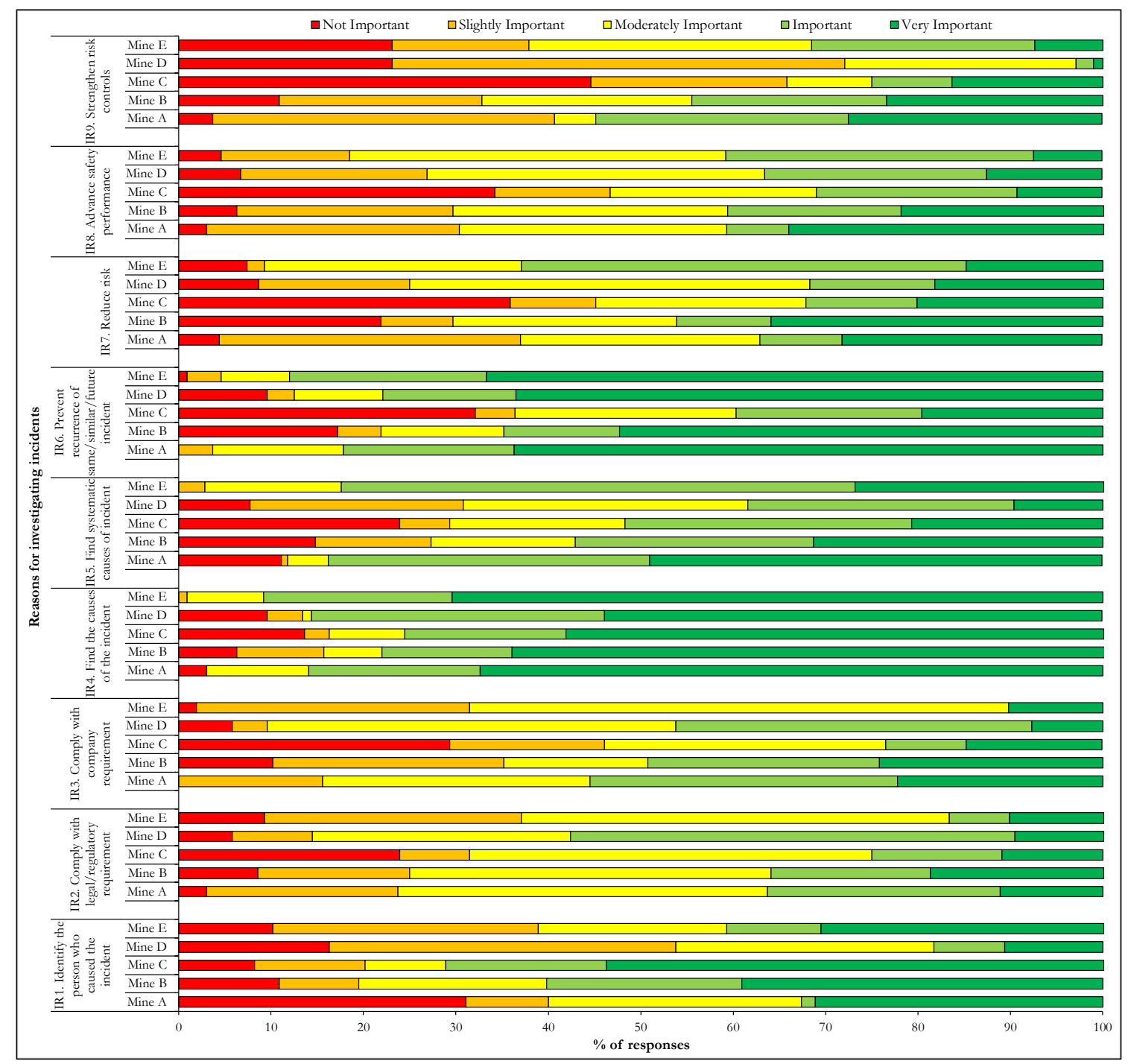

Figure 5. Comparison across mines of how important survey participants perceived the reasons for investigating incidents. 


\subsubsection{Testing for Statistically Significant Differences in Participants' Responses}

Results of the one-way ANOVA test, as illustrated in Table 3, showed statistically significant differences in the participants' responses with respect to the different mines, workgroups, and organizational levels for some of the measured variable. The result indicated a significant difference in the responses from the five mines at $p<0.005$ for all 14 variables (five causal factors and nine reasons for investigating incidents). With respect to the five different workgroups, there were no significant differences in the responses for all the 14 measured variables, except the CF1 (unsafe act of workers) and IR1 (identify the person who caused the incident) variables. Similarly, concerning the different organizational level of the participants, only five (CF1, CF2, CF3, IR1, and IR6) out of the 14 variables indicated statistically significant differences in the participants' responses. These results indicate that, whereas there are significant differences in the responses of the participants in terms of the different mines, there is little difference in the responses when considering the different organizational levels and workgroups of the survey respondents.

Turkey's HSD post hoc test further showed strong evidence of differences between the measured variable scores of some pairs of mines. For instance, for the variable CF1 (unsafe act), mines pairs $\mathrm{AC}, \mathrm{AD}, \mathrm{BD}, \mathrm{CD}, \mathrm{CE}$, and $\mathrm{DE}$ had statistically significant differences in their means score, whereas mine pairs $A B, A E, B C$, and $B E$ had no difference in their mean score. Similarly, for the variable IR1, mine pairs $A B, A C, B D, C E$, and $D E$ had significant differences in their mean scores, whereas $A D$, $\mathrm{AE}, \mathrm{BC}, \mathrm{BE}$, and $\mathrm{CD}$ did not. These results suggest that although there are general similarities in the responses across the mines, such as a focus on workers' unsafe act and identifying the person who caused the incident, some subtle differences equally exist and such differences ought to be considered when developing intervention measures to improve investigations. 
Table 3. Comparison across (a) mines, (b) work groups, (c) organizational level for one-way ANOVA test of the incident causal factors and reasons for investigation incidents (significant at $p<0.005$ ).

\begin{tabular}{|c|c|c|c|c|c|c|c|c|c|}
\hline \multirow{2}{*}{ Measure Variable } & \multicolumn{3}{|c|}{ (a) Mines } & \multicolumn{3}{|c|}{ (b) Workgroups } & \multicolumn{3}{|c|}{ (c) Organizational Levels } \\
\hline & F & $\mathrm{df}$ & $p$ & $\mathbf{F}$ & df & $p$ & F & df & $p$ \\
\hline CF1. Unsafe act of workers & 15.37 & 4 & $<0.001$ & 5.09 & 4 & $<0.001$ & 13.93 & 3 & $<0.001$ \\
\hline CF2. Equipment-related issues & 12.35 & 4 & $<0.001$ & 0.76 & 4 & 0.549 & 4.81 & 3 & 0.003 \\
\hline CF3. Work environment factors & 26.20 & 4 & $<0.001$ & 1.43 & 4 & 0.222 & 14.04 & 3 & $<0.001$ \\
\hline CF4. Management/organizational factors & 9.82 & 4 & $<0.001$ & 2.30 & 4 & 0.057 & 1.03 & 3 & 0.377 \\
\hline CF5. Others & 2.59 & 4 & 0.036 & 0.49 & 4 & 0.740 & 1.11 & 3 & 0.345 \\
\hline IR1. Identify the person who caused the incident & 21.98 & 4 & $<0.001$ & 5.77 & 4 & $<0.001$ & 15.18 & 3 & $<0.001$ \\
\hline IR2. Comply with legal/regulatory requirement & 8.50 & 4 & $<0.001$ & 2.19 & 4 & 0.069 & 0.75 & 3 & 0.520 \\
\hline IR3. Comply with company requirement & 18.01 & 4 & $<0.001$ & 1.40 & 4 & 0.234 & 0.70 & 3 & 0.551 \\
\hline IR4. Find the causes of the incident & 5.34 & 4 & $<0.001$ & 0.98 & 4 & 0.420 & 4.04 & 3 & 0.007 \\
\hline IR5. Find systematic causes of incident & 18.14 & 4 & $<0.001$ & 0.42 & 4 & 0.793 & 3.67 & 3 & 0.012 \\
\hline IR6. Prevent recurrence of same/similar/future incident & 40.18 & 4 & $<0.001$ & 1.70 & 4 & 0.148 & 8.29 & 3 & $<0.001$ \\
\hline IR7. Reduce risk & 8.38 & 4 & $<0.001$ & 2.93 & 4 & 0.020 & 1.58 & 3 & 0.193 \\
\hline IR8. Advance safety performance & 11.12 & 4 & $<0.001$ & 1.99 & 4 & 0.094 & 0.42 & 3 & 0.739 \\
\hline IR9. Strengthen risk controls & 24.42 & 4 & $<0.001$ & 3.04 & 4 & 0.017 & 1.25 & 3 & 0.290 \\
\hline
\end{tabular}


3.3.4. Testing for Association between the Incident Causal Factors and the Reasons for Investigating Incidents

Result of the correlation analysis as presented in Table 4 reveals the existence of statistically significant negative and positive correlations between some of the measured variables. The positive correlation $(\mathrm{r}=0.25)$ between the "unsafe act of workers" causal factor and the "identify the person who caused the incident" reason is of interest. This positive correlation indicates that participants who considered an unsafe act as a casual factor, which was identified as often/always during investigation, also indicated that identifying the person who caused the incident is an important/a very important reason for investigating incidents. Figure 6 is a scatter plot of the mean score of the unsafe act of workers (CF1) and identify the person who caused the incident (IR1) variables. The figure shows that Mine D had the highest score for both variables, whereas Mines C and B had the lowest score for both variables. The high scores at Mine $\mathrm{D}$ is no surprise as previous studies indicate that there is a focus on the worker when investigating an incident at the mine and that there is a culture of blame and finding culpability, which tends to affect the effectiveness of their investigations [26,27,41]. Generally, Figure 6 indicates that mines with a low unsafe act score had a low score for the identify the person variable, and mines which had a high score for the unsafe act variable also had a high score for the identify the person variable. This suggests that to reduce the focus on workers' unsafe act as an incident causal factor during investigation, efforts must be directed at addressing the understanding that the purpose for investigating an incident is to identify the person who caused the incident.

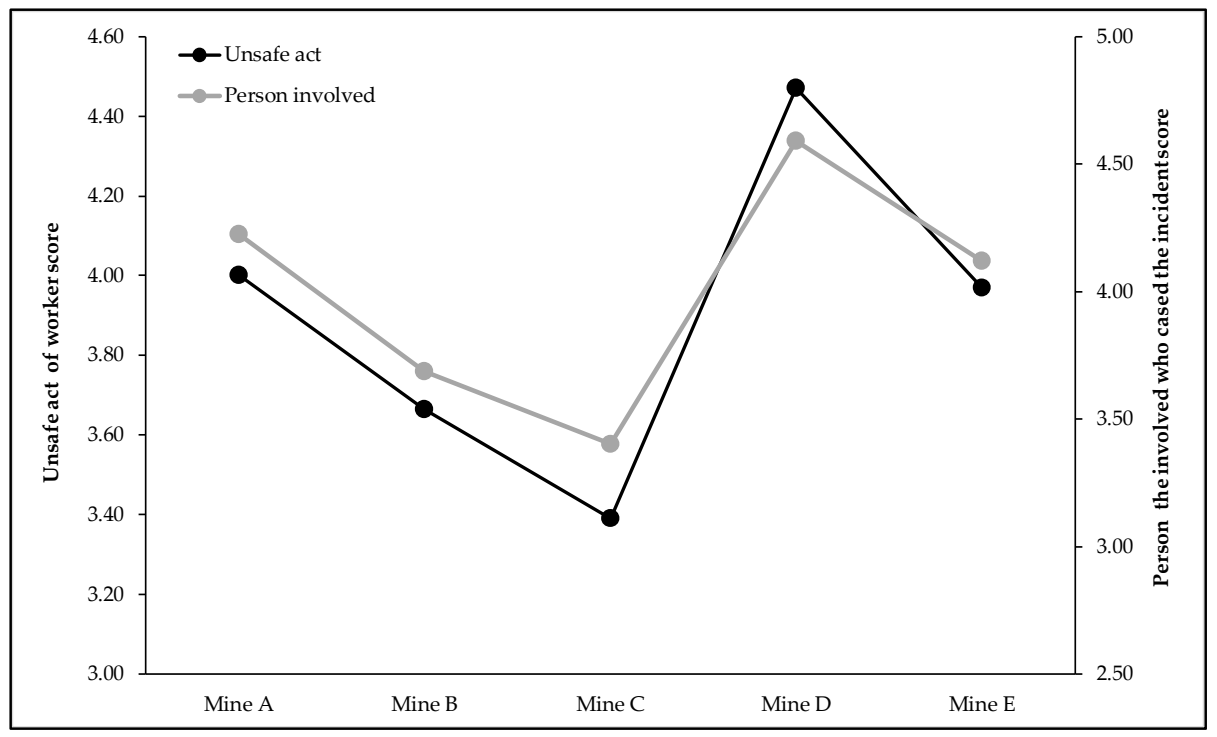

Figure 6. Scatter plot of the mean score for the unsafe act of workers and identify the person who caused the incident variables. 
Table 4. Mean, standard deviation, and Pearson's correlation (r) of the incident causal factors and the reasons for investigating incidents.

\begin{tabular}{|c|c|c|c|c|c|c|c|c|c|c|c|c|c|c|c|c|}
\hline Variable & $\mathbf{M}$ & SD & CR1 & CR2 & CR3 & CR4 & CR5 & IR1 & IR2 & IR3 & IR4 & IR5 & IR6 & IR7 & IR8 & IR9 \\
\hline CF1. Unsafe act of workers & 3.81 & 1.33 & 1.00 & & & & & & & & & & & & & \\
\hline CF2. Equipment-related issues & 3.06 & 1.29 & 0.07 & 1.00 & & & & & & & & & & & & \\
\hline CF3. Work environment factors & 3.24 & 1.15 & -0.38 ** & $0.29 * *$ & 1.00 & & & & & & & & & & & \\
\hline CF4. Management/organizational factors & 2.54 & 1.21 & -0.02 & $0.09 *$ & $0.18^{* *}$ & 1.00 & & & & & & & & & & \\
\hline CF5. Others & 2.65 & 1.17 & -0.02 & 0.06 & 0.06 & $0.18^{* *}$ & 1.00 & & & & & & & & & \\
\hline $\begin{array}{l}\text { IR1. Identify the person who caused the } \\
\text { incident }\end{array}$ & 3.36 & 1.48 & $0.25^{* *}$ & $0.19^{* *}$ & $0.27^{* *}$ & $0.14^{* *}$ & $0.20^{* *}$ & 1.00 & & & & & & & & \\
\hline $\begin{array}{l}\text { IR2. Comply with legal/regulatory } \\
\text { requirement }\end{array}$ & 3.07 & 1.14 & -0.01 & 0.06 & 0.04 & -0.05 & $-0.08^{*}$ & 0.06 & 1.00 & & & & & & & \\
\hline IR3. Comply with company requirement & 3.12 & 1.22 & 0.04 & $0.08^{*}$ & 0.01 & -0.05 & -0.03 & 0.07 & $0.64^{* *}$ & 1.00 & & & & & & \\
\hline IR4. Find the causes of the incident & 4.27 & 1.18 & $0.11^{* *}$ & -0.03 & $-0.08^{*}$ & -0.06 & $-0.09 *$ & 0.04 & $0.23 * *$ & $0.27 * *$ & 1.00 & & & & & \\
\hline IR5. Find systematic causes of incident & 3.56 & 1.32 & 0.05 & -0.03 & $-0.13 * *$ & -0.01 & $-0.08^{*}$ & $-0.17^{* *}$ & $0.15^{* *}$ & $0.13^{* *}$ & $0.43^{* *}$ & 1.00 & & & & \\
\hline $\begin{array}{l}\text { IR6. Prevent recurrence of } \\
\text { same/similar/future incident }\end{array}$ & 3.85 & 1.43 & $0.28 * *$ & $-0.12^{* *}$ & $-0.28 * *$ & -0.03 & -0.02 & $-0.34^{* *}$ & $0.23 * *$ & $0.27^{* *}$ & $0.44^{* *}$ & $0.57^{* *}$ & 1.00 & & & \\
\hline IR7. Reduce risk & 3.15 & 1.39 & -0.03 & $-0.09 *$ & -0.02 & 0.06 & -0.01 & $-0.13^{* *}$ & $0.34^{* *}$ & $0.33 * *$ & $0.30 * *$ & $0.36^{* *}$ & $0.57^{* *}$ & 1.00 & & \\
\hline IR8. Advance safety performance & 3.09 & 1.26 & $-0.09 *$ & $-0.13^{* *}$ & -0.01 & -0.01 & 0.01 & $-0.19^{* *}$ & $0.29^{* *}$ & $0.27^{* *}$ & 0.07 & $0.23 * *$ & $0.30^{* *}$ & $0.33^{* *}$ & 1.00 & \\
\hline IR9. Strengthen risk controls & 2.75 & 1.39 & $-0.11^{* *}$ & $-0.15^{* *}$ & -0.03 & 0.06 & -0.01 & -0.07 & $0.18^{* *}$ & $0.27 * *$ & $0.15^{* *}$ & $0.25 * *$ & $0.39^{* *}$ & $0.49^{* *}$ & $0.45^{* *}$ & 1.00 \\
\hline
\end{tabular}

* Correlation is significant at the 0.05 level, ${ }^{* *}$ correlation is significant at the 0.01 level. 


\section{Discussions}

A number of limitations exist when interpreting the results presented here. First, since this study relied on convenience and purposive sampling, sampling issues should be considered in interpreting the results. Mines were selected based on pre-determined selection criteria and only those who responded in the affirmative to an invitation participated in the research. Therefore, results may not necessarily be a good representation of what is happening across the Ghanaian mining industry. However, the diverse nature of the five participating mines and the individual respondents could contribute to the research being representative of the mining industry in Ghana. All interview participants were experienced investigators deeply involved in investigations at their mines, contributing to a rich understanding of the research topic. Again, the principles of redundancy and saturation of information were employed to contribute to the richness of the data. All interviewees were questioned on the same subjects and interviews were repeated several times until all themes and concepts were repeated multiple times without the emergence of new themes and concepts in subsequent interviews. In effect, all incident investigators of the respective mines present at the time of data collection were interviewed. The qualitative studies were also complemented with quantitative studies. All these contributed in ensuring that the identified causal factors and reasons of investigations are good representations of what is happening in the field. The second limitation lies in the use of self-report, which is often criticized due its susceptibility to social desirability bias [43,44]. However, since this study goes beyond the boundary of a single mine to include five mines, as well as the high response rate and large sample size, potential social desirability biases might have been minimized. Even when considering these limitations, this study presents some meaningful outcomes which will now be discussed.

The main objective of this research was to determine if there were any differences between the incident investigation perspectives of miners involved in actual investigations and miners with no/limited investigation responsibility. The results generally showed not many differences in the perspectives of these two groups. Overall, the analysis of both the interview and survey data showed a focus on workers' unsafe act as the primary incident causal factor across the five mines. This indicates how an unsafe act of workers has deeply permeated the investigations at the mines, probably due to the strong emphasis on Heinrich's 88:10:2 accident causal factors ratio across the mines [45]. According to Heinrich [45], $88 \%$ of accidents are caused by unsafe acts of workers, $10 \%$ by unsafe physical conditions, and $2 \%$ are unpreventable [41]. During fieldwork and data collection, it was observed how this 88:10:2 ratio was highly regarded across all five mines, as it was taught during all the safety trainings and site inductions we attended. It was therefore no surprise that workers' unsafe act was the frequent causal factor in both the qualitative and quantitative studies. Consistently, the findings showed that frontline workers with no/limited safety responsibilities are not very likely to produce new knowledge to improve safety as they believe completely whatever they are taught without critiquing it. The workers, at least so far as the data illustrate, accept whatever they are taught- that is whenever an accident happens, they tend to accept that it is their fault and are unable to identify systemic problems that contributed in the accident. The inability of workers to identify systemic accident causal factors offers an opportunity for more ground research, namely, why miners do not "see" systematic problems as accident causal factors, and thus how miners can be assisted to "see" systematic problems as accident causal factors. Again, it is suggested that for workers to be able to generate innovative safety responses, the mines must begin to strongly focus on the systemic nature of accident causal factors, in contrast to the strong emphasis on the proximate accident causal factors. Workers must be made to understand that accidents are caused by multiple interrelated factors spanning across several levels of a sociotechnical system, and that since a sociotechnical system consists of several levels, the actions and decisions of actors across the different levels interact to shape the performance of the system [41]. This we believe could contribute to the workers being more critical about safety, in order to produce new safety approaches.

Furthermore, the strong emphasis on unsafe acts is, however, problematic as it tends to emphasize on the proximate cause of the accident, with little/no consideration to the distal causes, such as 
systemic failures. The focus on unsafe acts during accident investigations does not support what has recently been learnt about the complexity of industrial accidents and accident causation for that matter. For instance, recent accidents and their investigation reports, such as the BP Texas City explosion in 2005, the BP Deepwater Horizon explosion in 2010, and the Columbia accident have indicated that a focus on unsafe acts as the primary causal factor during investigation is a short-sighted approach to investigations [46-48]. This is because the unsafe act focus does not yield any meaningful outcome to achieve an important improvement in organizational safety. In all the above listed accidents, causal factors related to decisions made above the worker level, such as flawed design, weakness in operation implementation, and team interfaces, were identified. It is therefore recommended that this focus on unsafe acts across the mines must give way to a systemic approach to investigation that focuses on organizational weaknesses and management decisions and how they contribute to an accident. In contrast to Heinrich's 88:10:2, Deminig 85:15 rule, which is applicable to incident investigations, offers some opportunity to improve investigations across the mines. After analyzing 1700 accidents, Deming observed that $85 \%$ of operational problems lie within systemic failures and management decisions, with 15\% lying within the responsibility of workers. Therefore, the mines' focus on workers' actions is only a superficial approach to a complex problem, and to improve safety, accident investigations, including prevention efforts, should focus on addressing systemic weaknesses rather than workers' actions and inactions.

Again, the focus on unsafe acts and man failure results in proposing and implementing superficial corrective measures, such as retraining workers and emphasizing on following the standard operating procedure, which only yields single-loop learning in contrast to double-loop learning [49,50]. This is because prevention efforts are directed at the proximate cause, rather than addressing systemic failures to improve the overall safety performance of the organization. To promote double-loop learning, it is highly recommended that the mines begin to have a deep focus on the organizational factors that create the precondition giving rise to unsafe acts. Again, there should be a focus on decision making above the worker level as noted by Reason in his book "Managing the Risks in Organisational Accident" [42]. Reason reports that latent conditions, including poor designs, maintenance failure, and clumsy automation, may exist for several years before being combined with active failures such as unsafe acts to penetrate the system layers of barriers to result in an accident [42]. This implies that to prevent accidents and improve safety, investigation efforts must be directed towards the identification of the latent condition combined with the active failures leading to the accident. However, as can be clearly seen from the analysis of the data, this situation hardly occurs across the mines, hence, an opportunity to improve investigations exists in the area. The result further showed a significant correlation between unsafe act as an incident causal factor and identifying the person who caused the incident as a reason for initiating investigation. This implies those whose investigations focus on unsafe acts tend to focus their attention on the worker, something which has been identified as a key contributor of the blame culture and an inhibitor of effective investigations [11,51]. This is because investigation attention is diverted from the root causes deeply buried within the organization. Therefore, it is suggested that to improve investigation, the blame culture must give way to "just culture" as suggested by Reason [42]. To achieve this just culture, incidents must be seen as free lessons, offering an opportunity to undertake a systemic appraisal to identify organizational weaknesses, which when addressed will ensure double-loop learning to improve organization safety [11].

\section{Conclusions}

This research sought to understand the perspective of Ghanaian mineworkers regarding incident investigations focusing on accident causal factors and the reasons for investigating incidents. The research also sought to determine whether talking to ordinary workers is able to yield new incident investigation approaches. It can be concluded from the findings that frontline workers are unlikely to generate new safety approaches, since they accept and believe whatever they are taught and are unable to analyze their working conditions and management decisions as contributing to 
unsafe acts. An opportunity for further research exists in understanding why miners are unable to identify systemic problems as accident causal factors. By analyzing the data, the research identified five accident causal factors and nine reasons for investigating incidents. Among the five identified causal factors, unsafe acts of workers was the frequently mentioned causal factor in both the interviews and survey, whereas organizational factors were the least considered causal factors. Concerning the reasons for investigating incidents, there was a focus on identifying the causes of the incident to prevent future incidents, without necessarily contributing to an overall improvement in safety. The results generally indicated the existence of single-loop learning in contrast to double-loop learning and revealed several opportunities to improve incidents investigation, which have been discussed. It was further observed that mines (A, D, and E) that emphasized on workers' unsafe acts as the major accident causal factor also emphasized on identifying the person involved in the accident as the main reason for their investigation. Conversely, mines (B and C) that had limited focus on workers' unsafe acts as accident causal factors also narrowly focused on identifying the person involved in the accident as a reason for their investigations. It can be concluded that to minimize/eliminate the strong focus on workers' unsafe acts as the major accident causal factor, efforts must be directed at addressing the understanding that the purpose for investigating an incident is to identify the person who caused the incident. Again, the results make the case that by teaching miners that individual behaviors are mostly the cause of accidents, an opportunity is lost to address systemic core causes and thus the incidence of accidents can be expected to continue unaltered.

Author Contributions: E.S. conceived the research idea, collected and analyzed the data, and composed the initial manuscript. F.N., M.A.A., and T.J.-A. assisted in data analysis and provided ongoing reviews, critical feedbacks, and edits of the manuscript. All authors have read and agreed to the published version of the manuscript.

Funding: This research received no external funding.

Acknowledgments: We acknowledge the assistance of the Inspectorate Division of the Minerals Commission of Ghana, the five mines and interview and survey respondents whose time, resources, and information were vital to the research. Eric Stemn is a recipient of an Australian Government Research Training Program Scholarship and UQ Centennial Scholarship at The University of Queensland, Australia.

Conflicts of Interest: The authors declare no conflict of interest.

\section{Appendix A. Summary of Survey Questions}

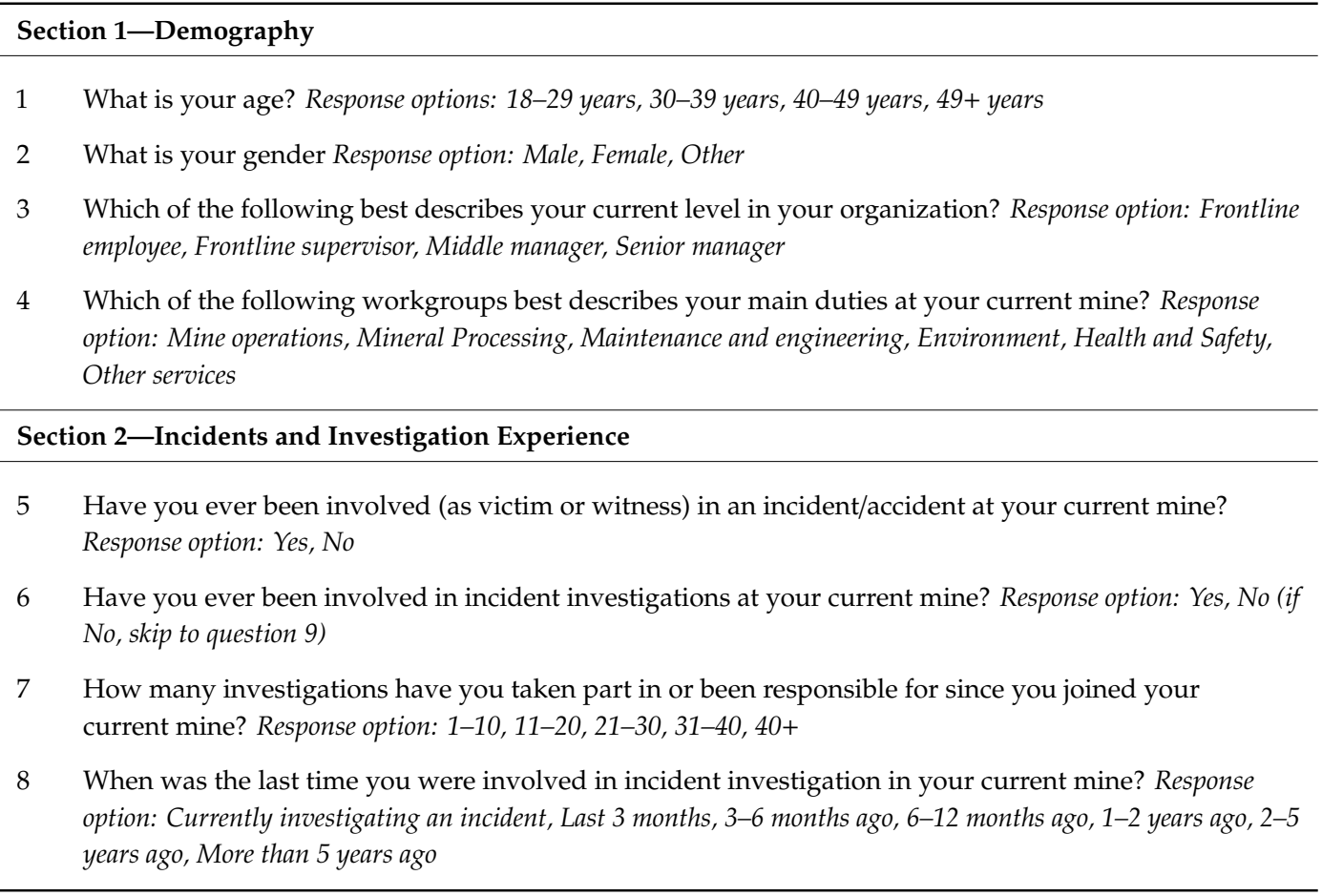


Section 3-Incident Causal Factors

9 How often do you think the following are identified as incident causal factors from incident investigation at your current mine?

- Unsafe act of workers

- $\quad$ Equipment related issues

- Work environment factors

- Organizational factors

- $\quad$ Other

Response option: 5-point Likert scale (1-Never, 2-Seldom, 3-Sometimes, 4-Often, 5-Always)

Section 4-Reasons for Investigating Incidents

10 How important do you consider the following as the reasons why incidents are investigated in your organization?

- To identify the person who caused the accident

- To comply with legal requirements

- To comply with company requirements

- To find causes of the incident

- To find systematic causes or factors of the incidents

- To prevent recurrence of same or similar event

- $\quad$ Reduce risk

- Advance HSE performance

- To strengthen failed controls and identify absent controls

Response option: 5-point Likert scale (1-Not important, 2-Slightly important, 3-Moderately important, 4-Important, 5-Very important)

\section{References}

1. Drupsteen, L.; Guldenmund, F.W. What Is Learning? A Review of the Safety Literature to Define Learning from Incidents, Accidents and Disasters. J. Contingencies Crisis Manag. 2014, 22, 81-96. [CrossRef]

2. Drupsteen, L.; Wybo, J.-L. Assessing propensity to learn from safety-related events. Saf. Sci. 2015, 71, 28-38. [CrossRef]

3. Le Coze, J.C. What have we learned about learning from accidents? Post-disasters reflections. Saf. Sci. 2013, 51, 441-453.

4. Lindberg, A.-K.; Hansson, S.O.; Rollenhagen, C. Learning from accidents-What more do we need to know? Saf. Sci. 2010, 48, 714-721. [CrossRef]

5. Lukic, D.; Margaryan, A.; Littlejohn, A. How organisations learn from safety incidents: A multifaceted problem. J. Workplace Learn. 2010, 22, 428-450. [CrossRef]

6. Lukic, D.; Margaryan, A.; Littlejohn, A. Individual agency in learning from incidents. Hum. Resour. Dev. Int. 2013, 16, 409-425. [CrossRef]

7. Drupsteen, L.; Groeneweg, J.; Zwetsloot, G.I.J.M. Critical Steps in Learning From Incidents: Using Learning Potential in the Process. From Reporting an Incident to Accident Prevention. Int. J. Occup. Saf. Ergon. 2013, 19, 63-77. [CrossRef]

8. Kjellén, U. Prevention of Accidents through Experience Feedback; Taylor \& Francis: London, UK, 2000.

9. Kletz, T.A. Learning from Accidents; Butterworth-Heinemann: Boston, MA, USA, 2001; Volume 3.

10. Reason, J. Human error: Models and management. BMJ 2000, 320, 768-770. [CrossRef]

11. Stemn, E.; Bofinger, C.; Cliff, D.; Hassall, M.E. Failure to learn from safety incidents: Status, challenges and opportunities. Saf. Sci. 2018, 101, 313-325. [CrossRef]

12. Cooke, D.L.; Rohleder, T.R. Learning from incidents: From normal accidents to high reliability. Syst. Dyn. Rev. 2006, 22, 213-239. [CrossRef]

13. Hopkins, A. Failure to Learn: The BP Texas City Refinery Disaster; CCH Australia Limited: Sydney, Australia, 2008.

14. Kletz, T.; Amyotte, P. What Went Wrong?: Case Histories of Process Plant Disasters and How They Could Have Been Avoided; Butterworth-Heinemann: Oxford, UK, 2019. 
15. Pasman, H.J. Learning from the past and knowledge management: Are we making progress? J. Loss Prev. Process Ind. 2009, 22, 672-679. [CrossRef]

16. Sepeda, A.L. Lessons learned from process incident databases and the process safety incident database (PSID) approach sponsored by the Center for Chemical Process. Safety. J. Hazard. Mater. 2006, 130, 9-14. [CrossRef] [PubMed]

17. Benner, L. Rating accident models and investigation methodologies. J. Saf. Res. 1985, 16, 105-126. [CrossRef]

18. Dien, Y.; Dechy, N.; Guillaume, E. Accident investigation: From searching direct causes to finding in-depth causes-Problem of analysis or/and of analyst? Saf. Sci. 2012, 50, 1398-1407. [CrossRef]

19. Kontogiannis, T.; Leopoulos, V.; Marmaras, N. A comparison of accident analysis techniques for safety-critical man-machine systems. Int. J. Ind. Ergon. 2000, 25, 327-347. [CrossRef]

20. Sklet, S. Comparison of some selected methods for accident investigation. J. Hazard. Mateials 2004, 111, $29-37$. [CrossRef]

21. Cedergren, A. Implementing recommendations from accident investigations: A case study of inter-organisational challenges. Accid. Anal. Prev. 2013, 53, 133-141. [CrossRef]

22. Drupsteen, L.; Hasle, P. Why do organizations not learn from incidents? Bottlenecks, causes and conditions for a failure to effectively learn. Accid. Anal. Prev. 2014, 72, 351-358.

23. Rollenhagen, C.; Alm, H.; Karlsson, K.-H. Experience feedback from in-depth event investigations: How to find and implement efficient remedial actions. Saf. Sci. 2017, 99, 71-79. [CrossRef]

24. Wahlström, B. Organisational learning-Reflections from the nuclear industry. Saf. Sci. 2011, 49, 65-74. [CrossRef]

25. Hämäläinen, P.; Saarela, K.L.; Takala, J. Global trend according to estimated number of occupational accidents and fatal work-related diseases at region and country level. J. Saf. Res. 2009, 40, 125-139. [CrossRef] [PubMed]

26. Stemn, E.; Bofinger, C.; Cliff, D.; Hassall, M.E. Investigating the Maturity of Incident Investigations of the Ghanaian Mining Industry and Its Effect on Safety Performance. Safety 2019, 5, 3. [CrossRef]

27. Stemn, E.; Hassall, M.E.; Cliff, D.; Bofinger, C. Incident investigators' perspectives of incident investigations conducted in the Ghanaian mining industry. Saf. Sci. 2018, 112, 173-188. [CrossRef]

28. Ibrahim, A. Newmont Ghana, DRA Limited fined $\$ 2.7 \mathrm{~m}$ over Ahafo Mine Collapse. 2018. Available online: https://www.myjoyonline.com/business/2018/june-4th/newmont-ghana-dra-limited-fined-morethan-25m-over-ahafo-mine-collapse.php (accessed on 19 January 2020).

29. Mining Technology. Six Workers Killed in Accident at Newmont Mining's Project in Ghana. 2018. Available online: https://www.mining-technology.com/news/six-workers-killed-accident-newmont-minings-projectghana/ (accessed on 19 January 2020).

30. Agency, G.N. Fatal Accidents in Mining Industry Increase-Koney. 2018. Available online: https:// www.ghanabusinessnews.com/2018/08/31/fatal-accidents-in-mining-industry-increase-koney/ (accessed on 18 January 2020).

31. Amponsah-Tawiah, K.; Jain, A.; Leka, S.; Hollis, D.; Cox, T. Examining psychosocial and physical hazards in the Ghanaian mining industry and their implications for employees' safety experience. J. Saf. Res. 2013, 45, 75-84. [CrossRef] [PubMed]

32. Aubynn, T. Mining and Sustainable Development: The Case of Ghana. 2013. Available online: http: //im4dc.org/wp-content/uploads/2013/07/Mining-and-Sustainable-Development-Ghana.pdf (accessed on 18 April 2016).

33. Owiredu, D. Annual Chamber of Mines Predential Review; 83rd Annual Meeting of the Ghana Chamber of Mines; 2011. Available online: www.ghanachamberofmines.org (accessed on 21 March 2016).

34. Stemn, E. Analysis of Injuries in the Ghanaian Mining Industry and Priority Areas for Research. Saf. Health Work 2018, 10, 151-165. [CrossRef] [PubMed]

35. Graneheim, U.H.; Lundman, B. Qualitative content analysis in nursing research: Concepts, procedures and measures to achieve trustworthiness. Nurse Educ. Today 2004, 24, 105-112. [CrossRef]

36. Patton, M.Q. How to Use Qualitative Methods in Evaluation; Sage Publication Ltd.: Los Angeles, CA, USA, 1987.

37. Downe-Wamboldt, B. Content analysis: Method, applications, and issues. Health Care Women Int. 1992, 13, 313-321. [CrossRef]

38. Elo, S. Kääriäinen, M.; Kanste, O.; Pölkki, T.; Utriainen, K.; Kyngäs, H. Qualitative content analysis: A focus on trustworthiness. Sage Open 2014, 4, 2158244014522633. [CrossRef] 
39. Kondracki, N.L.; Wellman, N.S.; Amundson, D.R. Content Analysis: Review of Methods and Their Applications in Nutrition Education. J. Nutr. Educ. Behav. 2002, 34, 224-230. [CrossRef]

40. Schreier, M. Qualitative Content Analysis in Practice; SAGE Publications: Los Angeles, CA, USA, 2012.

41. Stemn, E.; Bofinger, C.; Cliff, D.; Hassall, M.E. Examining the relationship between safety culture maturity and safety performance of the mining industry. Saf. Sci. 2019, 113, 345-355. [CrossRef]

42. Reason, J. Managing the Risks of Organizational Accidents; Ashgate: Aldershot, Hants, UK, 1997.

43. Fisher, R.J. Social Desirability Bias and the Validity of Indirect Questioning. J. Consum. Res. 1993, 20, 303-315. [CrossRef]

44. Grimm, P. Social Desirability Bias. In Wiley International Encyclopedia of Marketing; Sheth, J., Malhotra, N., Eds.; Wiley Publishing Company: Hoboken, NJ, USA, 2010.

45. Heinrich, H.W. Industrial Accident Prevention: A Scientific Approach; McGraw-Hill: New York, NY, USA, 1931.

46. Dien, Y.; Llory, M. Effects of the Columbia Space Shuttle Accident on High Risk Industries or can We Learn Lessons from other Industries. In Hazards XVIII; Institution of Chemical Engineers (IChemE): Manchester, UK, 2004; pp. 23-25.

47. Gehman, H.W., Jr.; Barry, J.L.; Deal, D.W.; Hallock, J.N.; Hess, K.W.; Hubbard, G.S.; Logsdon, J.M.; Osheroff, D.D.; Ride, S.K.; Tetrault, R.E. Columbia Accident Investigation Board Report. Volume 1; NASA: Washington, DC, USA, 2003; p. 248.

48. Graham, B.; Reilly, W.K.; Beinecke, F.; Boesch, D.F.; Garcia, T.D.; Murray, C.A.; Ulmer, F. Deep Water: The Gulf Oil Disaster and the Future of Offshore Drilling. In Report to the President: National Commission on the BP Deepwater Horizon Oil Spill and Offshore Drilling; National Commission on the BP Deepwater Horizon Oil Spill and Offshore Drilling: New Orleans, LA, USA, 2011; p. 381.

49. Argyris, C.; Schön, D.A. Organizational Learning: A Theory of Action Perspective; Addison-Wesley: Reading, MA, USA, 1978; Volume 173.

50. Argyris, C.; Schön, D.A. Organizational Learning II: Theory, Method, and Practice; Addison-Wesley: Reading, MA, USA, 1996.

51. Manuele, F.A. Reviewing Heinrich: Dislodging Two Myths from the Practice of Safety. Prof. Saf. 2011, 56, 52-61.

(C) 2020 by the authors. Licensee MDPI, Basel, Switzerland. This article is an open access article distributed under the terms and conditions of the Creative Commons Attribution (CC BY) license (http://creativecommons.org/licenses/by/4.0/). 